\title{
EQUIDADE E RAZÃO PRÁTICA NA DECISÃO JUDICIAL: Algumas Reflexões de Teoria Geral do Direito e de História do Pensamento Jurídico ${ }^{1}$
}

\author{
Klaus Cohen-Koplin ${ }^{2}$
}

\section{RESUMO}

$\mathrm{O}$ artigo traz reflexões sobre equidade e razão prática, na decisão judicial, no âmbito da teoria geral do direito e da história do pensamento jurídico.

Descritores: Equidade. Decisão judicial. Tribunal: decisões. Teoria geral do Direito. Pensamento jurídico.

\section{INTRODUÇÃO: o problema central}

A presente comunicação versará sobre a equidade como meio de correção da lei, por parte do juiz, no caso concreto.

Logo se poderia discutir se seria realmente necessário algum tipo de correção em face da situação específica, e por qual razão. A

1 Versão editada da comunicação apresentada na Faculdade de Direito da Pontifícia Universidade Católica do Rio Grande do Sul (PUCRS), In: COLÓQUIO SULAMERICANO DE REALISMO JURÍDICO, 7.; CONGRESSO SUL-AMERICANO DE FILOSOFIA DO DIREITO, 4., 6-7 out. 2008, Porto Alegre, RS. Anais... Porto Alegre: Instituto Jacques Maritain do Rio Grande do Sul, 2008. 1 CD-ROM.

2 Doutor em Direito pela Universidade Federal do Rio Grande do Sul (UFRGS). Professor Titular de Teoria Geral do Direito e Direito Processual Civil na Faculdade de Direito do Centro Universitário Ritter dos Reis (UniRitter), Campus de Porto Alegre, Rio Grande do Sul. Professor Auxiliar de Direito Processual Civil na Faculdade de Direito da Instituição Educacional São Judas Tadeu. Professor Substituto de Direito Processual Civil na Faculdade de Direito da UFRGS. Currículo: http://buscatextual.cnpq.br/buscatextual/ visualizacv.jsp?id=K4751020T3. Endereço profissional: Rua Santos Dumont, 888, Niterói, CEP 92120-110, Canoas, RS, Brasil. Endereço eletrônico: koplin2@yahoo.com. 
motivação consiste naquela fornecida por Aristóteles, na Ética a Nicômaco: por causa do distanciamento entre a regra geral, estabelecida pelo legislador tendo em vista o que ordinariamente acontece, e um evento particular que, sem embargo de estar formalmente incluído nas palavras do texto legal, seja tão específico que se afaste daquela situação comum que o legislador teve em conta ao elaborá-lo.

As grandes questões que se colocam, portanto, são as seguintes: seria essa fratura suficiente para permitir ao aplicador (mais especificamente, o juiz) afastar-se da regra geral? Estaria ele autorizado, em face das circunstâncias específicas, a abandonar a disposição legal e a estabelecer, por conta própria, uma disposição considerada mais adequada a essa realidade? Em caso positivo, sobre que bases?

É possível ilustrar essa problemática com dois exemplos subministrados pelo direito comparado. De fato, ninguém ignora que determinados sistemas jurídicos, como o brasileiro e o espanhol, consagram disposições gerais a respeito da utilização da equidade nas decisões judiciais, em matéria cível. Assim, o artigo 127 do Código de Processo Civil brasileiro vigente veda, à primeira vista, o seu emprego, estabelecendo, de forma contundente, que "o juiz só decidirá por equidade nos casos previstos em lei” (Brasil, 2005). O artigo 3.2 do Código Civil espanhol, por seu turno, de forma aparentemente contrastante com essa regulamentação, admite claramente o emprego da equidade, dispondo, de maneira bem mais detalhada do que o do país sul-americano, em tradução livre, que "a equidade deverá ser ponderada na aplicação das normas; todavia as resoluções dos Tribunais somente poderão repousar de maneira exclusiva nela quando a lei o permitir expressamente"3 (Espanha, 1995, tradução livre).

Tomando como motivação essa aparente contradição, cumpre examinar, em primeiro lugar, as principais manifestações do positivismo jurídico dos séculos XIX e XX, bem como seus críticos, a fim de que se perceba o tratamento insatisfatório que conferiram à problemática antes levantada. Em seguida, procede-se à apresentação da resposta fornecida pelo jusnaturalismo clássico (aristotélico-tomista), analisando-se a maneira como essa linha de pensamento se propõe a solucionar as questões implicadas decorrentes da tensão entre a lei geral e o caso concreto. Segue-se, finalmente,

3 “'La equidad habrá de ponderarse en la aplicación de las normas, si bien las resoluciones de los Tribunales sólo podrán descansar de manera exclusiva en ella cuando la ley expresamente lo permita” (Espanha, 1995). 
uma apreciação das principais conclusões alcançadas, enfocando-se a interpretação mais adequada do ponto de vista da filosofia do direito, que se deve conferir aos dispositivos legais mencionados acima.

\section{RESPOSTAS INSATISFATÓRIAS FORNECIDAS PELO POSITIVISMO JURÍDICO}

Em primeiro lugar, destaca-se aquela que pode ser considerada, talvez, como a versão mais radical do positivismo legalista do século XIX, a saber, a Escola da Exegese (école de l'exégèse).

Com efeito, para os exegetas franceses, a primeira das questões antes anunciadas simplesmente não se coloca, já que a aplicação do direito resulta de um processo puramente lógico, de caráter silogístico, consistente na subsunção dos fatos à norma jurídica. De fato, em termos de Teoria Geral do Direito, uma vez constatado pelo aplicador que o caso específico se enquadra formalmente na hipótese jurídica (suporte fático abstrato) da norma, não lhe resta outra alternativa que não a concretização da consequência jurídica prevista pelo legislador (Perel- man, 1976, p. 24-25). Trata-se daquilo que Vittorio Frosini denomina “juízo de legalidade” (1974, p. 42-43).

A situação se torna mais grave quando referida especificamente ao juiz. Como se sabe, em razão da doutrina da separação de poderes (idealizada pelo Barão de Montesquieu e implementada na Constituição dos Estados Unidos da América e na Declaração dos Direitos do Homem e do Cidadão de 1789), não compete ao magistrado julgar a lei, mas decidir de acordo com ela. Nessa linha, recorda Norberto Bobbio a respeito dos fatores histórico-ideológicos que contribuíram para o estabelecimento do método exegético, que, por causa dessa doutrina, “o juiz não poderia criar o direito, caso contrário invadiria a esfera de competência do Poder Legislativo, mas devia, de acordo com a imagem de Montesquieu, ser somente a boca através da qual fala a lei” (Bobbio, 1995, p. 79).

Dentro desse contexto, como afirma Carlos Ignacio MassiniCorreas, "não pode haver equidade se a única fonte do direito é a lei escrita e se, ademais, ela deve ser aplicada dedutivamente a partir dos textos considerados em seu mais estrito sentido linguístico" (Massini-Correas, 1983, p. 223). ${ }^{4}$

4 "no puede haber equidad si la única fuente del derecho es la ley escrita y si, además, ella debe ser aplicada deductivamente a partir de los los textos considerados en su más estricto sentido linguístico" (Massini-Correas, 1983, p. 223). 
De outro lado, conforme ensina Franz Neumann, a equidade sempre foi concebida, pela teoria jurídica liberal, como empecilho para realização do valor segurança jurídica, por comprometer a calculabilidade e a confiança nas relações econômicas (e, consequentemente, a expectativa de cumprimento das obrigações contratuais) (D’Agostino, 1977c, p. 28-29; Grau, 2004, p. 27). ${ }^{5}$ Daí a instituição de um verdadeiro culto ao texto da lei como condição então vista como necessária à manutenção da liberdade individual.

Ademais disso, deve-se sublinhar a imensa contribuição prestada pelo Iluminismo a esse estado de coisas. De fato, o movimento em questão, ao acentuar a racionalidade teórica matemática, desvalorizou completamente a razão prática tal como entendida pela filosofia aristotélico-tomista (ou seja, a excelência no raciocínio prático ou prudência) e, consequentemente, a equidade que, conforme se verá mais adiante, encontra-se em estrita dependência dessa última.

Não se mostra substancialmente a situação nos territórios alemães. De fato, a Escola Pandectista (Pandektenwissenschaft)compartilhou da mesma visão, embora de maneira um tanto distinta. Nesse sentido, Bernhard Windscheid, um dos nomes mais destacados dessa linha de pensamento, após afirmar que somente o direito equitativo seria o verdadeiro direito, e que a equidade seria a "estrela guia” (Leitstern) a indicar-lhe o caminho a seguir, iluminando-o como um ideal, julgou-a ao final inútil, pois "este mundo não é o mundo no qual os ideais se realizam" (Windscheid, 1854, p. 10-11). O direito, para ser aplicável, deve estabelecer-se como regra. Pode certamente ocorrer, sublinha Windscheid, que o caso individual seja subsumido a uma regra que não corresponda realmente ao seu bom direito. Nesse caso, o sentimento de equidade que resta ferido não deve irromper em acusações irracionais ou em lamentos infantis; deve, antes, consolar-se com a constatação de ter sido sacrificado para tornar possível a existência do direito em geral (D’Agostino, 1977c, p. 22).

Tais excessos em que incorreram tanto a Escola da Exegese quanto a Ciência das Pandectas justificaram o surgimento, no final do século XIX e no começo do século XX, de diversas correntes críticas de pensamento, apresentando alternativas metodológicas em relação ao paradigma positivista. Assim, no

5 NEUMANN, Franz Leopold [1900-1954]. Autor de The Rule of Law: political theory and the legal system in modern society. UK: Leamington, 1936. 
contexto francês, pode-se recordar a Livre Investigação Cientifica (libre recherche scientifique) de François Gény. Na Alemanha, encontramse a Jurisprudência dos Interesses (Interessenjurisprudenz), proposta por Rudolph von Jhering e desenvolvida por Philipp Heck, e o Movimento do Direito Livre (Freirechtsbewegung), de Eugen Ehrlich y Herrmann Kantorowicz. ${ }^{6}$

Se acarretaram importante revisão na metodologia do Direito da virada do século passado, a verdade é que nenhum desses movimentos logrou fornecer adequada resposta aos questionamentos antes formulados.

Gény, por exemplo, imaginou haver na equidade duas noções distintas: ou um tipo de instinto, sem qualquer referência ao exercício da razão, ou a adaptação da ideia de justiça aos fatos, tomando em conta suas circunstâncias particulares, sendo que, nesse último caso, restaria fora dos domínios da ciência jurídica, da variedade ao infinito dos elementos concretos de cada caso particular (Gény, 1919, p. 111-113). Como observa Francesco D’Agostino, em suma, essa visão implica negar à equidade qualquer possibilidade de sistematização científica (1977c, p. 21).

A Jurisprudência dos Interesses, de outra parte, pretendeu efetuar uma virada metodológica em relação ao formalismo pandectista, substituindo o "primado da lógica" pelo "primado da vida e da indagação da vida”. Nessa linha, esclarece Karl Larenz, a partir de uma passagem de Philipp Heck, que o objetivo final "da atividade judicial e da resolução pelo juiz dos casos concretos é [...] 'a satisfação das necessidades da vida, a satisfação das apetências e das tendências apetitivas, que materiais, quer ideais, presentes na comunidade jurídica' " (Larenz, 1997, p. 64).

Já o Movimento do Direito Livre (especialmente nas elaborações de Hermann Kantorowicz e, mais ainda, de Hermann Isay) reduziu o julgamento do caso concreto a mera expressão do sentimento jurídico ou a manifestação da vontade do julgador, uma vez que o valor justiça não seria suscetível de ser apreendido por meio da razão (Larenz, 1997, p. 80-81).

Ambas as vertentes do positivismo europeu continental do século XIX se refletem, de certa maneira, na concepção desenvolvida na obra de Hans Kelsen.

Não surpreende, nesse contexto, que o autor austríaco proclame a relativa indeterminação do ato de aplicação do direito. Segundo exposto no Capítulo VIII da segunda edição de sua Teoria Pura, o direito a 
aplicar poderia ser comparado a uma moldura destinada a ser preenchida pelo aplicador, o que daria origem a várias possibilidades de interpretação. A seleção daquela a ser adotada dependeria fundamentalmente de um em ato de vontade, portanto, de um ato político. Nessa perspectiva, a verdadeira interpretação autêntica do direito seria aquela realizada pelo juiz ao julgar determinado caso específico. A sentença, por sua vez, não seria senão criação de uma norma jurídica individual (Kelsen, 1998, p. 388-393).

O papel atribuído à ciência do direito, como se sabe, consistiria na "pura determinação cognoscitiva do sentido das normas jurídicas”; resumir-se-ia, portanto, à tarefa vazia de fornecer ao órgão encarregado da aplicação do direito uma gama de sentidos possíveis, competindo a esse último a seleção do sentido mais adequado, do ponto de vista político subjetivo (Kelsen, 1998, p. 395-396).

Não é necessário insistir que essa visão, pelo menos nos termos mais radicais propostos por Kelsen, não foi aceita pela teoria do direito contemporânea, que exige a apresentação de razões justificativas para a decisão judicial, que já não pode ser encarada, portanto, pelo menos sob o prisma discursivo, como simples ato de vontade ou decisão política do juiz.

Subjaz a todas essas concepções a ideia de que o Direito constitui mera expressão da vontade, conforme a conhecida fórmula de Thomas Hobbes: é a autoridade (isto é, a "vontade"), não a verdade (que, nesse contexto, pode perfeitamente ser entendida como "razão") que estabelece a lei (auctoritas, non veritas, facit legem). E isso tanto no processo de criação do direito ("vontade da lei”) quanto no mecanismo de aplicação do direito ao caso ("vontade do juiz", segundo a concepção de Kelsen). Por conseguinte, degradando o jurídico ao mero arbítrio, nenhuma dessas visões mostra-se capaz de solucionar adequadamente, em termos objetivos, os problemas levantados na introdução deste trabalho.

\section{RESPOSTA DO JUSNATURALISMO CLÁSSICO}

Diante da inaptidão demonstrada pelo pensamento jurídico moderno, parece adequado investigar mais de perto a proposta do pensamento clássico.

De fato, é sabido que o posicionamento aristotélico a respeito da questão antes formulada consiste na adaptação da lei ao caso específico, em atenção à classe de justiça denominada epiéikeia. E isso, no que diz respeito ao segundo questionamento apresentado na introdução deste estudo, em razão da excessiva generalidade de que se encontra imbuído o preceito legal, 
em contraste com a especificidade do caso concreto.

Convém, portanto, acompanhar a solução dada por Aristóteles à aparente aporia entre o justo e o equitativo. O equitativo é de fato justo, mas não segundo a lei. Tratase, na verdade, de uma correção do justo estabelecido pela lei, no ponto em que se mostra defeituosa em virtude de sua generalidade. Em verdade, embora sendo a lei uma norma universal, não lhe é possível tratar universalmente de certos casos particulares. Em tais situações, levase em conta o que ocorre na maior parte dos casos, sem ignorar, contudo, os erros de aproximação que disso possam resultar. Nem por isso a regra deixa de ser correta em si mesma, pois o erro não está na lei ou no legislador, mas na natureza mesma da coisa: a ação prática humana, que é sempre irregular e contingente. Portanto, quando a lei estabelece algo em geral, e em seguida sucede algum evento que não se encaixa nessa previsão, mostra-se legítimo, no ponto em que o legislador se omitiu, pecando por excesso de generalização, corrigir a omissão e considerar prescrito aquilo que o próprio legislador diria se estivesse presente e que teria feito constar no texto da lei se conhecesse o caso em questão. Assim, como nem tudo pode ser estabelecido pela lei (pois existem casos a respeito dos quais é impossível legislar), mostra-se necessário estabelecer uma resolução particular (pséphisma) adaptada à situação concreta ${ }^{7}$ (Aristóteles, 2003).

Em resumo, conforme essa concepção, não é que a lei (lei no sentido próprio do termo, ou seja, a boa lei, a lei razoável) esteja equivocada ou seja injusta em si mesma. Pelo contrário: o caso é que se mostra demasiado particular, alheio a qualquer possibilidade de universalização, por isso mesmo afastando-se da situação de fato padrão tomada em conta pelo legislador quando da elaboração da regra. S. Tomás de Aquino, interpretando o pensamento aristotélico, acrescenta que, em alguns casos, observar a lei é contra a igualdade da justiça e contra o bem comum, que a própria lei tem em vista ${ }^{8}$ (Aquino, 1952).

Nessa linha, a primeira possibilidade que se abre ao julgador (não por acaso chamado pelo estagirita de “a justiça animada”) (Aristóteles, 2003), como forma de implementar a

7 ARISTÓTELES. Ética a Nicômaco. 1137 b 10-25.

8 AQUINO. Summa Theologiae, II-II, q. 120, a. 1, resp.

9 ARISTÓTELES. Ética a Nicômaco. 1132 a 20. 
dita correção, consiste em não aplicar a regra geral ao caso particular. Não resta excluída, outrossim, segundo se deduz das ideias expostas por Aristóteles na Retórica e na própria Ética a Nicômaco, a mitigação dos rigores da lei como forma de melhor adaptação do texto aos fatos ${ }^{10}$ (Barzotto, 2000, p. 172-173).

Como sublinha, novamente, Massini-Correas, esse tipo de decisão não significa que o magistrado vá fazer algum juízo de valor acerca da justiça da lei, considerada em si mesma, senão apenas de sua aplicabilidade à situação específica $^{11}$ (1983, p. 212). A equidade não implica, por conseguinte, nenhum tipo de revolução do aplicador contra a lei, mas verdadeira insistência na preservação de seu campo legítimo de autonomia e de incidência.

Conforme observa John Finnis, verifica-se o distanciamento apenas da letra da lei, a fim de restar preservada a verdadeira intenção do legislador. Ou seja, a epiéikeia procura atender ao espírito mesmo da lei, deixando em segundo plano a sua formulação linguística, essa última sempre limitada pelo horizonte daquilo que se pode dizer em termos gerais $^{12}$ (Finnis, 1994).

Dessa forma, observa-se ser apenas aparente a aporia acima referida, pois o estabelecimento de disposições universais visando ao bem comum revela-se de fundamental importância para o convívio na comunidade política. Daí a definição tomista de lei como "ordenação da razão prática, voltada para o bem comum, promulgada por aquele que cuida da comunidade"13 (Aquino, 1952). De resto, e na mesma linha, recorda a Compilação de Justiniano da regra geral segundo a qual se deve

10 Não se exclui, ainda, uma terceira função desempenhada pela epiéikeia, a saber, o preenchimento das lacunas da lei, problema, no entanto, que resta excluído dos limites deste estudo.

11 Na base dessa percepção, aliás, encontra-se a doutrina de S. Tomás de Aquino, exposta na Summa Theologiae (II-II, q. 120, a. 1, ad 2).

12 "the justice of acting according to a common rule (II-II q. 157 a. 2 ad 2), i.e., according to all relevant laws, divine or human (II-II q. 79 a 1c and 3c) - in the first instance according to their letter, but more fundamentally and ultimately according to the intent (always to be assumed to be just and reasonable) of their author(s): the radical justice of equity \{aequitas, epieikeia\} wich departs from the common rule in its common (usual) meaning in order do uphold the rule in its true sense all things considered" (Finnis, 1994, p. 216).

13 AQUINO. Summa Theologiae, I-II, q. 90, a. 4, resp.: “quaedam rationis ordinatio ad bonum commune, ab eo qui curam communitatis habet, promulgata”. 
julgar com base nas leis, não a partir de exemplos particulares (non exemplis, sed legibus iudicandum est).$^{14}$

Como conclusão parcial, percebe-se que a equidade, segundo a tradição do jusnaturalismo clássico aristototélico-tomista, consiste em uma forma de justiça superior à “justiça legal” (mas não ao justo natural) (Aquino, 1969, p. 324), ou seja, à aplicação pura e simples da lei positiva ao fato que, não obstante esteja enquadrado formalmente na literalidade de seu texto, produz consequências que não foram sequer imaginadas pelo legislador.

É bem de ver que a linha de pensamento clássica em questão não identifica na utilização da equidade nenhum viso de subjetivismo, arbitrariedade ou voluntarismo por parte do julgador. Pelo contrário, a epiéikeia resulta do exercício do raciocínio prático aperfeiçoado pelas virtudes morais e intelectuais (especialmente pela mais destacada dessas últimas no campo prático, que é a phrónesis, também chamada discernimento ou prudência)e,portanto, procura oferecer critérios objetivos para orientar a atuação humana (D’Agostino,1977b, p. 53-55).

Como bem sintetiza Francesco D’Agostino, "a equidade não remete a decisões irracionais ou parciais, mas a uma específica forma de juízo, nem silogístico, nem entimemático, nem teórico, nem tópico, mas prático, fundado, por conseguinte, sobre a prudência, mais exatamente sobre aquela particular atualização dela que Aristóteles denominou gnome, que não seria excessivo definir como "prudência jurídica"' (D’Agostino, 1977c, p. 41).

Segundo se percebe, o funcionamento do "juízo de equidade", segundo a expressão de Vittorio Frosini (1974, p. 42-43), somente pode ser explicado, em termos clássicos, à luz do raciocínio prático-prudencial. Este, por sua vez, encontra-se dirigido à percepção da verdade prática, isto é, a identificação da decisão a ser tomada em dada situação concreta. Decisão essa que não é constituída, mas simplesmente captada pelo julgador a partir da realidade, sem se distanciar do horizonte do problema, com o que resta assegurada a perfeita objetividade da decisão por equidade.

O exercício da prudência remete, no entanto, para a presença constante da lei natural e do justo por natureza. Daí a visão, realçada especialmente pela tradição tomista, da equidade como uma forma de acesso ao direito natural.

Em síntese, seja como forma de temperamento dos rigores da lei,

14 C. $7,45,13$. 
seja como "momento operativo" da phrónesis (D’Agostino, 1977a, p. 74), seja como forma de acesso racional ao justo por natureza, é certo que a equidade se revela insuscetível de ser eliminada da experiência jurídica, pois, como destaca Sergio Raúl Castaño, “este racional (ou seja, a lei), enquanto regra prudencial, não poderia deixar de atender à indeterminação inerente à matéria a que se aplica”, a saber: a conduta humana ${ }^{15}$ (Castaño, 1995, p. 95). Justamente por isso, o aquinate a definiu como regra superior dos atos humanos (superior regula humanorum actuum $)^{16}$ (Aquino, 1952).

\section{CONCLUSÕES}

Como visto, a aplicação da equidade remete não a um julgamento subjetivo, voluntarista, emotivista, mas a uma decisão objetivamente verificável, constituindo exercício da prudência enquanto excelência do raciocínio prático.

Justamente por isso, a equidade não logrou encontrar espaço no pensamento jurídico moderno, seja naquelas duas versões surgidas no século XIX, seja nas diversas linhas de pensamento que, na virada do século
XIX para o século seguinte, tentaram estabelecer-se como propostas alternativas ao estrito normativismo professado pela escola positivista. E isso, fundamentalmente, em virtude do voluntarismo e consequente negação da racionalidade prática, inerente a todas essas visões.

A ideia, demonstrada e defendida no presente estudo, consiste em que apenas uma teoria do direito jusnaturalista, de corte clássico, aristotélico-tomista, encontra-se em condições de lidar adequadamente com a permanente tensão entre o geral da lei e a particularidade do caso, e isso por meio do recurso à equidade, compreendida como "momento opertivo” do raciocínio prático virtuoso.

À luz dessas considerações, percebe-se que a única interpretação razoável que se pode extrair do artigo 127 do Código de Processo Civil brasileiro é no sentido de que a proibição aí estabelecida dirige-se ao emprego do sentimento pessoal de justiça do juiz como motivo determinante da decisão judicial (percepção, que, convém insistir, nada tem a ver com a equidade clássica). Em outros termos, o veto legal se dirige ao emprego daquele juízo político, meramente voluntarista, de

15 “este racional (o sea, la ley), en tanto regla prudencial, no podría dejar de atender a la indeterminación raigal de la materia a la que se aplica” (Castaño, 1995, p. 95).

16 AQUINO, Summa Thelogiae, II-II, q. 120, a. 2, resp. 
que falava o ilustre autor da Teoria Pura do Direito.

Ao contrário, a equidade entendida como correção da lei geral em virtude das especificidades do caso particular não é susceptível de ser eliminada da experiência jurídica, já que pertence, como se pode extrair do conjunto dos textos aristotélicos, à essência mesma do ato de julgar. Conclui-se, portanto, que proibir a equidade no sentido clássico não é a interpretação que razoavelmente se pode atribuir ao

\section{REFERÊNCIAS}

AQUINO, Santo Tomás de [1225-1274]. Sententia Libri Ethicorum: cura et studio fratrum predicatorum. In: AQUINO, Santo Tomás de. Opera omnia: iussu Leonis XIII P. M. edita. Romae: Ad Sanctae Sabinae, 1969. v. 47. AQUINO, Santo Tomás de [12251274]. Summa theologiae: cura fratrum eiusdem ordinis. Matriti: Biblioteca de Autores Cristianos, 1952. v. 2 (Prima Secundae) e v. 3 (Secunda Secundae).

ARISTÓTELES [384-322aC]. Etica nicomachea. Introduzione, traduzione, note e apparati di Claudio Mazzarelli. 3. ed. Milano: Bompiani (testi a fronte), 2003. BARZOTTO, Luis Fernando. $O$ direito ou o justo: o direito como mencionado preceito. Mais explícita, sem dúvida, se mostra a dicção do artigo 3.2 do Código Civil espanhol, que reconhece positivamente a incidência da equidade na aplicação de todas as regras legais, ainda que exclua a sua aplicação exclusiva.

Em suma, observa-se que, sem afirmar a racionalidade da lei e da decisão judicial, é impossível compreender e aceitar o exercício da equidade por ocasião da aplicação do direito pelo Poder Judiciário. objeto da ética no pensamento clássico. Anuário do Programa de Pós-Graduação em Direito [UNISINOS], São Leopoldo, p. 159-184, 2000.

BOBBIO, Norberto [1909-2004]. O positivismo jurídico: lições de filosofia do direito. Trad. e notas de Márcio Pugliesi, Edson Bini e Carlos E. Rodrigues. São Paulo: Ícone, 1995.

BRASIL. Código de processo civil. São Paulo: Vértice, 2005. 480 p.

CALVO GARCÍA, Manuel. Los fundamentos del método jurídico: una revisión crítica. Madrid: Tecnos, 1994.

CASTAÑO, Sergio Raúl. La racionalidad de la ley. Buenos Aires: Ábaco, 1995. 
CORPUS iuris civilis. Recognovi Paulus Krueger. 6. ed. Berolini apud Weidmannos, 1954. v. 2 (Codex iustinianus).

D’AGOSTINO, Francesco. Appunti per una teoria dell'epikeia. In: D’AGOSTINO, Francesco. Dimensioni dell'equità. Torino Giappichelli, 1977a. p. 59-109.

D’AGOSTINO, Francesco. È censurabile la motivazione delle sentenze d'equità? In: D’AGOSTINO, Francesco Dimensioni dell'equità. Torino: Giappichelli, 1977b. p. 47-57.

D’AGOSTINO, Francesco. L'Equità come limite trascendentale del diritto. In: D’AGOSTINO, Francesco Dimensioni dell'equità. Torino: Giappichelli, 1977c. p. 13-45.

ESPANHA. Codigo civil. 18. ed. Madrid: Civitas, 1995. 636 p. (Civitas. Biblioteca de Legislación).

FINNIS, John. Aquinas. Oxford: Oxford University Press, 1994.

FROSINI, Vittorio [1922-2001]. L'equità nella teoria generale del diritto. Revista da Faculdade de Direito da Universidade de
Uberlândia, Uberlândia, v. 4, n. 1/2, p. 35-51, 1974.

GÉNY, François [1861-1959]. Méthode d'interprétation et sources en droit privé positif. 2. ed. Paris: Librairie Générale de Droit et de Jurisprudence, 1919. v. 2.

GRAU, Eros Roberto. Equidade, razoabilidade e proporcionalidade. Revista do Advogado (AASP), São Paulo, n. 78, p. 27-30, set. 2004.

KELSEN, Hans [1881-1973]. Teoria pura do direito. Trad. de João Baptista Machado. 6. ed. São Paulo: Martins Fontes, 1998.

LARENZ, Karl [1903-1993]. Metodologia da ciência do direito. Trad. de José Lamego. 3. ed. Lisboa: Gulbenkian, 1997.

MASSINI-CORREAS, Carlos Ignacio. La prudencia jurídica. Buenos Aires: Abeledo-Perrot, 1983.

PERELMAN, Chaïm [1912-1984]. Logique juridique: nouvelle rhétorique. Paris: Dalloz, 1976.

WINDSCHEID,Bernhard[1817-1892]. Recht und rechtswissenschaft. Greifswald: Königl. UniversitätsBuchdruckerei von F. W. Kunike, 1854. 